\title{
Strong Prolyl Hydroxylase Domain 1 Expression Predicts Poor Outcome in Radiotherapy-treated Patients with Classical Hodgkin's Lymphoma
}

\author{
HAMID BUR ${ }^{1,2}$, KIRSI-MARIA HAAPASAARI ${ }^{2,3}$, TAINA TURPEENNIEMI-HUJANEN ${ }^{1,2}$, OUTI KUITTINEN ${ }^{1,2}$, \\ PÄIVI AUVINEN ${ }^{4,5}$, KATJA MARIN $^{4,5}$, YLERMI SOINI $^{2,3,5,6}$ and PEETER KARIHTALA ${ }^{1,2}$ \\ Departments of ${ }^{1}$ Oncology and Radiotherapy, and ${ }^{3}$ Pathology, \\ Medical Research Center Oulu, Oulu University Hospital, Oulu, Finland; \\ ${ }^{2}$ Cancer and Translational Medicine Research Unit, University of Oulu, Oulu, Finland; \\ ${ }^{4}$ Department of Oncology, Kuopio University Hospital, Kuopio, Finland; \\ ${ }^{5}$ Cancer Center, and ${ }^{6}$ Department of Pathology and Forensic Medicine, \\ Institute of Clinical Medicine, University of Eastern Finland, Kuopio, Finland
}

\begin{abstract}
Background: Hypoxia-inducible factors (HIFs) and prolyl hydroxylase domain (PHD) proteins control cellular oxygen homeostasis and a wide range of other processes. Materials and Methods: We immunohistochemically assessed the expression of HIF $1 \alpha, H I F 2 \alpha$, PHD1, PHD2 and PHD3 in 115 cases of classical Hodgkin's lymphoma, all treated in the first line with doxorubicin, bleomycin, vinblastine and darcabazine (ABVD) chemotherapy. Results: In advanced-stage patients treated with involved-field radiotherapy (IFRT), nuclear HIF $1 \alpha$ expression in reactive cellular infiltrate predicted prolonged relapse-free survival (RFS) (p=0.026). Strong cytoplasmic PHDl expression in Reed-Sternberg cells was associated with poor RFS among patients treated with IFRT and advanced-stage patients treated with $A B V D$ and IFRT ( $p=0.0028$ and $p=0.0058$, respectively). In Cox regression analysis, $P H D 1$ was a more significant predictor of relapse (risk ratio $=18.383 ; 95 \%$ confidence interval $(C I)=1.521-222.246 ; p=0.022)$ than the International Prognostic Score. Conclusion: HIF and PHD expression appear to be novel prognostic biomarkers in classical Hodgkin's lymphoma.
\end{abstract}

Hodgkin's lymphoma (HL) is classified as either classical

This article is freely accessible online.

Correspondence to: Peeter Karihtala, Department of Oncology and Radiotherapy, Oulu University Hospital, PO Box 22, 90029 Oulu, Finland. Tel: +358 83152011, Fax: +358 83156449, e-mail: peeter.karihtala@oulu.fi

Key Words: Hypoxia, HIF, PHD, Hodgkin's lymphoma, prognosis.
Hodgkin's lymphoma (cHL) and nodular lymphocytepredominant Hodgkin's lymphoma (1). Most (95\%) patients in Western countries present with cHL. Worldwide, age at diagnosis shows a bimodal distribution, the first peak occurring at 15-30 years of age and the second after 60 years (2).

With modern treatments, the prognosis of HL is among the most favourable in comparison to other malignancies (cure rate at least $80 \%$ ). However, in particular, the overall survival of young patients is reduced because of the increased incidence of cardiovascular diseases and secondary malignancies resulting from treatment-related long-term toxicity $(3,4)$. After relapse, survival is significantly worse, even though there are new targeted agents for the treatment of relapsed cHL (5).

Hypoxia, a low level of oxygen, is the result of imbalance between availability and consumption of oxygen. It occurs in both non-pathological and pathological conditions. The most important hypoxia regulators are hypoxia-inducible factors (HIFs). These transcription factors regulate both the consumption and delivery of oxygen (6). They have two subunits, $-\alpha$ and $-\beta$. Hypoxia leads to HIF $\alpha$ stabilization and its attachment to constitutively expressed HIF $\beta$. HIF $1 \alpha$ and HIF $2 \alpha$ combine with HIF $\beta$ and consequently activate HIF (6). Activated HIF triggers target gene expression, with the potential to accelerate cancer progression, affecting angiogenesis, metabolism, proliferation, apoptosis and reactive oxygen species (ROS) homeostasis (7-12). Increased expression of HIF $1 \alpha$ and HIF $2 \alpha$ has been linked to many types of cancer, including ovarian, brain and breast cancer (13). HIF $1 \alpha$ and HIF2 $\alpha$ have also been suggested to be prognostic factors in various cancer types (8).

Prolyl hydroxylase domain proteins (PHD1, PHD2 and PHD3) are also involved in oxygen homeostasis, triggering 
the proteosomal degradation of HIF1 $\alpha$ and HIF2 $\alpha$ (14). PHD2 in particular is known to act as an oxygen sensor for HIF stabilization (15). In addition to controlling the oxygen level, PHD proteins are part of the DNA damage response and regulate metabolism under oxidative stress in an HIFindependent fashion $(16,17)$. PHD proteins have been proposed to be tumour suppressors, but they are also associated with chemoresistance and tumour growth $(18,19)$.

In the present study, we retrospectively explored the roles of HIF1 $\alpha$, HIF2 $\alpha$, PHD1, PHD2 and PHD3 expression in patients with previously untreated cHL. Special emphasis was placed on the localization of expression, association with previously recognized prognostic factors of cHL and possible usability of immunostaining in terms of prognostic or predictive value.

\section{Materials and Methods}

Patient collection. The study material consisted of lymph node samples from 115 patients with histologically confirmed cHL before the initiation of any treatment. All patients were treated with doxorubicinbleomycin-vinblastine-dacarbazine (ABVD) chemotherapy in the firstline setting. Sixty-five patients also underwent involved-field radiotherapy (IFRT) after their chemotherapy (Table I). All lymphomas were diagnosed and treated in Finland in 1997-2015. Sixty-nine patients were diagnosed and treated at Oulu University Hospital and 42 patients at Kuopio University Hospital. Four patients were diagnosed and treated at the Central Hospitals of Kajaani, Kemi or Rovaniemi. Diagnoses were reviewed by a specialist haematopathologist. Accurate and updated patient information was gathered in each case from the hospital records.

Limited-stage risk factors included bulky mediastinal mass, elevated sedimentation rate, four or more involved nodal regions and age of 50 years or more. The International Prognostic Score (IPS) was calculated, based on the following factors: serum albumin $\leq 40 \mathrm{~g} / \mathrm{l}$, haemoglobin level $\leq 105 \mathrm{~g} / 1$, male sex, age $\geq 45$ years, stage IV, leucocytosis $\geq 15 \times 10^{9} / 1$ and lymphocytopenia $\leq 0.6 \times 10^{9} / 1$. Complete response (CR) was defined as no detectable tumour after first-line ABVD treatment. The Ethics Committee of the Northern Ostrobothnia Hospital District approved the study design (reference number 42/2010).

Immunohistochemistry. HL samples collected from the patients at the time of diagnosis were fixed in formalin and embedded in paraffin. Representative tumour areas from the paraffin blocks were cut in 3- $\mu \mathrm{m}$ sections and placed on SuperFrostPlus glass slides (Menzel-Gläser, Braunschweig, Germany). The slides were deparaffinised in Histo-Clear (National Diagnostics, Atlanta, GA, USA) and rehydrated through a graded series of alcohol solutions and rinsed in distilled water. Next, the slides were microwaved for 10 minutes in Tris-EDTA solution at $\mathrm{pH} 9$ (PHD1, PHD2, PHD3 and $\mathrm{HIF} 1 \alpha$ ) or for 20 minutes in citrate buffer solution at $\mathrm{pH} 6$ (HIF1 $\alpha$ ) to retrieve the epitopes and after 20 minutes' cooling at room temperature, endogenous peroxidase activity was neutralized in $3 \% \mathrm{H}_{2} \mathrm{O}_{2}$ solution for 5 minutes. The next step was incubation with primary antibodies (Table II) in a humidity chamber at room temperature for 1 hour (PHD1 and PHD2), overnight at room temperature $(\mathrm{HIF} 1 \alpha)$, or overnight at $4^{\circ} \mathrm{C}$ (PHD3 and HIF $\left.2 \alpha\right)$.
Immunostaining was continued using a Dako REAL ${ }^{\mathrm{TM}}$ EnVision $^{\mathrm{TM}}$ Detection System (Dako Denmark, A/S, Glostrup, Denmark) according to the instructions of the manufacturer. Diaminobenzidine was used to detect the immunoreaction. Between all stages of the immunostaining procedure, the slides were washed with PBSTween. Finally, the slides were counterstained with Mayer's haematoxylin, dehydrated and mounted.

Evaluation of immunohistochemical staining. Evaluation of immunostaining was performed by an experienced haematopathologist $(\mathrm{KMH})$ together with another investigator $(\mathrm{HB})$ blinded to the clinical data. Immunostaining was graded (i) separately in Reed-Sternberg (RS) cells and in the surrounding reactive cellular infiltrate; (ii) separately in nuclei and cytoplasm; and (iii) separately according to the extent $(0-100 \%)$ and the intensity of immunostaining (1: weak, 2 : moderate, 3 : strong, and 4 : very strong immunostaining intensity).

Statistical analysis. For statistical analyses, the staining intensity (04) was multiplied by the extent of immunostaining (0-100\%), resulting in a continuous variable of $0-400$. This continuous variable was used in all statistical analyses involving the Mann-Whitney $U$ test. Associations between protein expression and patient survival were analysed using the Kaplan-Meier method, and the statistical significance of differences was evaluated using the log-rank test. In survival analyses, continuous variables were divided into two classes (low or high expression) based on the median expression of each variable. Relapse-free survival (RFS) was calculated from the date of diagnosis to the date of the first confirmed relapse of cHL. Cox regression analysis was applied in multivariate analysis. Statistical analyses were carried out using IBM SPSS Statistics 24.0.0.0 software (IBM Corp., Armonk, NY, USA) and the results were considered significant when the two-sided $p$-value was less than 0.05 .

\section{Results}

Clinical and histological data are presented in Table I. The median follow-up time was 64 months (range $=4-153$ months). After chemotherapy, $81(70.4 \%), 30(26.1 \%)$ and four $(3.5 \%)$ of the patients had CR, partial response and progressive disease, respectively. After IFRT, CR was achieved by 66 (91.7\%) of the patients, while six (8.3\%) had only a partial response. There were seven (6.1\%) lymphomaspecific deaths and four (3.5\%) deaths due to other causes (e.g. infection). Nineteen (16.5\%) patients suffered a relapse during follow-up.

The extent of HIF1 $\alpha$, HIF2 $\alpha$, PHD1, PHD2 and PHD3 expression in RS cells and in reactive cellular infiltrate are presented in Table III and representative examples of the immunostaining patterns are shown in Figure 1.

Strong cytoplasmic HIF2 $\alpha$ staining in RS cells was associated with fewer complete responses after IFRT $(p=0.014)$ in the whole cohort and in the subgroup with limited-stage disease $(p=0.036)$, but not among the patients with advanced-stage cHL. In those with limited-stage cHL, strong nuclear HIF1 $\alpha$ staining in reactive cellular infiltrate correlated inversely with the achievement of $\mathrm{CR}$ after firstline ABVD chemotherapy ( $p=0.021)$. HIF $1 \alpha$ and HIF $2 \alpha$ did 
Table I. Demographics of the patients.

\begin{tabular}{|c|c|c|c|c|c|c|}
\hline \multirow{2}{*}{$\begin{array}{l}\text { Characteristic } \\
\text { Median age (range) at diagnosis, years }\end{array}$} & \multicolumn{2}{|c|}{ Limited stage } & \multicolumn{2}{|c|}{ Advanced stage } & \multicolumn{2}{|c|}{ Total } \\
\hline & 26 & $(11-85)$ & 28 & $(16-70)$ & 28 & $(11-85)$ \\
\hline \multicolumn{7}{|l|}{ Gender, n (\%) } \\
\hline Male & 24 & $52.1 \%$ & 30 & $50.8 \%$ & 61 & $53.0 \%$ \\
\hline Female & 32 & $57.1 \%$ & 29 & $29.2 \%$ & 54 & $47.0 \%$ \\
\hline \multicolumn{7}{|l|}{ Histology (ICD-10 code), n (\%) } \\
\hline $\mathrm{C} 81.1$ & 47 & $83.9 \%$ & 41 & $69.5 \%$ & 88 & $76.5 \%$ \\
\hline $\mathrm{C} 81.2$ & 4 & $7.1 \%$ & 14 & $23.7 \%$ & 18 & $15.7 \%$ \\
\hline $\mathrm{C} 81.7$ & 5 & $8.9 \%$ & 1 & $1.7 \%$ & 6 & $5.2 \%$ \\
\hline C81.9 & 0 & $0 \%$ & 3 & $5.1 \%$ & 3 & $2.6 \%$ \\
\hline \multicolumn{7}{|l|}{ B-Symptoms, n (\%) } \\
\hline Absent & 54 & $96.4 \%$ & 22 & $37.3 \%$ & 76 & $66.1 \%$ \\
\hline Present & 2 & $3.6 \%$ & 37 & $62.7 \%$ & 39 & $33.9 \%$ \\
\hline \multicolumn{7}{|l|}{ Stage, n (\%) } \\
\hline Limited & & & & & 56 & $48.7 \%$ \\
\hline Advanced & & & & & 59 & $51.3 \%$ \\
\hline \multicolumn{7}{|l|}{ Limited-stage risk factors, $\mathrm{n}(\%)$} \\
\hline None & 24 & $42.9 \%$ & & & & \\
\hline$\geq 1$ & 32 & $57.1 \%$ & & & & \\
\hline \multicolumn{7}{|l|}{ International Prognostic Score, n (\%) } \\
\hline $0-2$ & & & 50 & $89.2 \%$ & & \\
\hline $3-5$ & & & 9 & $20.0 \%$ & & \\
\hline WHO performance status $\geq 1, \mathrm{n}(\%)$ & 4 & $7.1 \%$ & 24 & $40.7 \%$ & 28 & $24.3 \%$ \\
\hline \multicolumn{7}{|l|}{ Number of ABVD cycles received, $n(\%)$} \\
\hline $2-3$ & 5 & $8.9 \%$ & 1 & $1.7 \%$ & 6 & $5.2 \%$ \\
\hline $4-5$ & 34 & $60.7 \%$ & 2 & $3.4 \%$ & 36 & $31.3 \%$ \\
\hline $6-7$ & 15 & $26.8 \%$ & 33 & $55.9 \%$ & 48 & $41.7 \%$ \\
\hline 8 & 2 & $3.6 \%$ & 23 & $39.0 \%$ & 25 & $17.6 \%$ \\
\hline \multicolumn{7}{|c|}{ Complete response with first-line ABVD, n (\%) } \\
\hline None & 14 & $25.0 \%$ & 20 & $33.9 \%$ & 34 & $29.6 \%$ \\
\hline Yes & 42 & $75.0 \%$ & 39 & $66.1 \%$ & 81 & $70.4 \%$ \\
\hline \multicolumn{7}{|l|}{ Radiotherapy, n (\%) } \\
\hline No & 11 & $19.6 \%$ & 32 & $54.2 \%$ & 43 & $37.4 \%$ \\
\hline Yes & 45 & $80.4 \%$ & 27 & $45.8 \%$ & 72 & $62.6 \%$ \\
\hline \multicolumn{7}{|c|}{ Complete response after radiotherapy, n (\%) } \\
\hline No & 3 & $6.7 \%$ & 3 & $11.1 \%$ & 6 & $8.3 \%$ \\
\hline Yes & 41 & $93.3 \%$ & 24 & $88.9 \%$ & 66 & $91.6 \%$ \\
\hline \multicolumn{7}{|l|}{ Relapse, n (\%) } \\
\hline No & 50 & $89.3 \%$ & 46 & $78.0 \%$ & 96 & $83.5 \%$ \\
\hline Yes & 6 & $10.7 \%$ & 11 & $22.0 \%$ & 19 & $16.5 \%$ \\
\hline \multicolumn{7}{|l|}{ Deaths, n (\%) } \\
\hline Lymphoma-specific & 1 & $1.8 \%$ & 6 & $10.2 \%$ & 7 & $6.1 \%$ \\
\hline Other causes & 3 & $5.4 \%$ & 1 & $1.6 \%$ & 4 & $3.5 \%$ \\
\hline
\end{tabular}

ABVD: Doxorubicin, bleomycin, vinblastine and darcabazine. C81.1: Nodular sclerosis classical Hodgkin lymphoma; C81.2: Mixed cellularity classical Hodgkin lymphoma; C81.7: Other (classical) Hodgkin lymphoma; C81.9: Hodgkin lymphoma, unspecified.

not show associations with limited-stage risk factors, IPS, stage or B-symptoms. Low-level cytoplasmic PHD1 staining in $\mathrm{RS}$ cells was associated with limited-stage risk factors $(p=0.042)$ and low-level cytoplasmic PHD1 and PHD3 immunostaining in reactive cellular infiltrate was also associated with a low rate of CR to chemotherapy in advanced-stage patients $(p=0.0020$ and $p=0.019$, respectively). Low-level nuclear PHD3 staining in RS cells was associated with a reduced degree of CR after the IFRT in patients with advanced-stage cHL $(p=0.030)$. PHD1, PHD2 and PHD3 showed no association with advanced IPS, stage or B-symptoms.

Survival analysis. Strong nuclear HIF1 $\alpha$ expression in reactive cellular infiltrate was associated with prolonged RFS in patients with advanced-stage cHL who had received IFRT $(p=0.026$, Figure 2A). When combined with IPS in multivariate analysis, HIF1 $\alpha$ expression in this subgroup 
Table II. Antibodies used in immunohistochemical analyses using the Dako REAL ${ }^{T M}$ EnVision ${ }^{T M}$ Detection System (Dako Denmark A/S, Glostrup, Denmark).

\begin{tabular}{lcc}
\hline Primary antibody & Source of primary antibody & Dilution \\
\hline PHD1, NB100-310 & Novus Biologicals, Oxford, UK & $1: 300$ \\
PHD2, NB100-138 & Novus Biologicals, Oxford, UK & $1: 300$ \\
PHD3, NBP1-30440 & Novus Biologicals, Oxford, UK & $1: 500$ \\
HIF1 $\alpha, 610958$ & BD Transduction Laboratories, Franklin Lakes, NJ, USA & $1: 40$ \\
HIF2 $\alpha$, ab8365 & Abcam, Cambridge, UK & $1: 100$ \\
\hline
\end{tabular}

appeared to have more prognostic power, although neither variable remained significant in this model [for HIF1 $\alpha$ : risk ratio $(R R)=0.223,95 \%$ confidence interval $(C I)=0.043-$ 1.157, $p=0.074$; and for IPS: $\mathrm{RR}=1.301,95 \% \mathrm{CI}=0.251$ $6.730, p=0.754]$. Strong nuclear HIF1 $\alpha$ expression in RS cells was not associated statistically significantly with prolonged RFS in patients with advanced-stage cHL who had received IFRT ( $p=0.11$, Figure $2 \mathrm{~B})$.

Strong cytoplasmic PHD1 expression in RS cells was associated with poor RFS among patients treated with IFRT and among those with advanced-stage $\mathrm{cHL}$ who had received IFRT ( $p=0.0028$ and $p=0.0058$, respectively, Figure $2 \mathrm{C}$ and D). In Cox regression analysis, the statistically significant effect greatly exceeded that of IPS in the patients treated with IFRT (for PHD1: $R R=10.073,95 \% \mathrm{CI}=1.549-65.520$, $p=0.016$; and for IPS: $\mathrm{RR}=0.340,95 \% \mathrm{CI}=0.387-1.388$, $p=0.34$ ) and also in the patients with both advanced-stage and treated with IFRT (for PHD1: RR 18.383, 95\% $\mathrm{CI}=1.521-222.246, p=0.022$; and for IPS: $\mathrm{RR}=0.263,95 \%$ $\mathrm{CI}=0.021-3.229, p=0.297)$.

\section{Discussion}

To our knowledge, this is the first report in which the expression of HIF1 $\alpha$, HIF2 $\alpha$, PHD1, PHD2 and PHD3 in cHL has been examined. The results show that HIF1 $\alpha$ and PHD1 are linked to relapse-free time, but that HIF1 $\alpha$, HIF2 $\alpha$, PHD1 and PHD3 may also have roles in the evolution of resistance to first-line treatment.

Both PHD1 and PHD3 have significant independent roles in inhibiting signalling of nuclear factor kappa-light-chainenhancer of activated B-cells (NF-kB) $(20,21)$. NF- $\mathrm{kB}$ has a significant role in the pathogenesis of RS cells in $\mathrm{cHL}$ and is constitutively active, ensuring the survival of RS cells (22). PHD3 also promotes growth inhibition through epidermal growth factor receptor (23) and mediates alpha-ketoglutarateinduced apoptosis and tumour suppression (24). Considering the essential role of NF-kB in $\mathrm{cHL}$ pathogenesis, it may be a connecting factor between low nuclear PHD3 expression in RS cells and worsened probability of achieving CR after
Table III. Percentages of cases showing any expression of hypoxiainducible factor $1 \alpha(H I F 1 \alpha), H I F 2 \alpha$, prolyl hydroxylase domain 1 (PHD1), PHD2 and PHD3.

\begin{tabular}{lccccc}
\hline & \multicolumn{2}{c}{ Reed-Sternberg cells } & & \multicolumn{2}{c}{ Reactive cellular infiltrate } \\
\cline { 2 - 3 } \cline { 5 - 6 } & Nuclei & Cytoplasm & & Nuclei & Cytoplasm \\
\hline HIF1 $\alpha$ & $73.9 \%$ & $0 \%$ & & $66.6 \%$ & $0 \%$ \\
HIF2 $\alpha$ & $0 \%$ & $85.8 \%$ & & $0 \%$ & $0 \%$ \\
PHD1 & $0 \%$ & $9.6 \%$ & & $0 \%$ & $100 \%$ \\
PHD2 & $97.6 \%$ & $0 \%$ & & $0 \%$ & $99.1 \%$ \\
PHD3 & $86.5 \%$ & $0 \%$ & & $0 \%$ & $86.5 \%$ \\
\hline
\end{tabular}

IFRT in patients with advanced-stage disease. On the other hand, there is significant crosstalk between reactive cellular infiltrate and RS cells. If cHL treatment drives (sensitive) reactive cellular infiltrate to apoptosis, the balance of crosstalk will suffer, which might explain why low levels of cytoplasmic PHD1 and PHD3 expression in reactive cellular infiltrate were associated with a lower rate of $\mathrm{CR}$ to chemotherapy in patients with advanced-stage cHL.

Stronger cytoplasmic PHD1 expression in RS cells was linked to poorer RFS in the patients with advanced-stage cHL who were treated with ABVD and IFRT. In more detail, PHD1 was expressed in RS cells in six patients treated with ABVD and IFRT, and three of them experienced relapse during follow-up. In patients with advanced-stage treated with ABVD and IFRT, PHD1 was expressed in four cases; three of these suffered relapse and two died of lymphoma. Based on the current results, cytoplasmic PHD1 expression thus seems to have diverse roles in reactive cellular infiltrate and in RS cells, being associated with sensitivity to ABVD in the former and poorer prognosis in the latter. In patients with pancreatic endocrine tumours, prostate adenocarcinoma and non-small-cell lung carcinoma, PHD1 has also been linked to poorer survival (25-27).

Strong HIF1 $\alpha$ and HIF2 $\alpha$ expression was associated with a low rate of $\mathrm{CR}$ to first-line treatment, especially in patients 

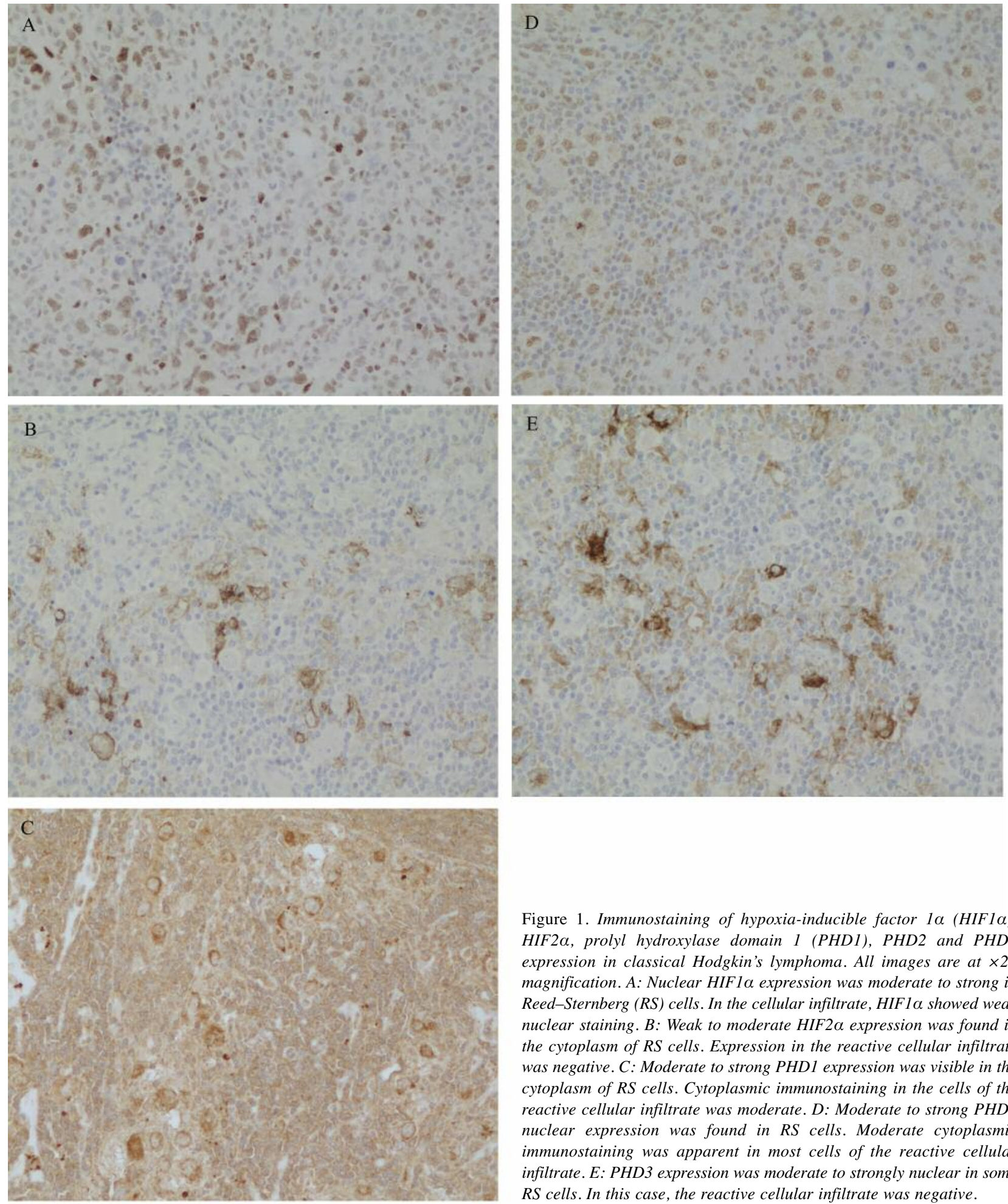

Figure 1. Immunostaining of hypoxia-inducible factor $1 \alpha(H I F 1 \alpha)$, $H I F 2 \alpha$, prolyl hydroxylase domain 1 (PHD1), PHD2 and PHD3 expression in classical Hodgkin's lymphoma. All images are at $\times 20$ magnification. A: Nuclear HIFl $\alpha$ expression was moderate to strong in Reed-Sternberg (RS) cells. In the cellular infiltrate, HIFl $\alpha$ showed weak nuclear staining. B: Weak to moderate HIF $2 \alpha$ expression was found in the cytoplasm of RS cells. Expression in the reactive cellular infiltrate was negative. C: Moderate to strong PHD1 expression was visible in the cytoplasm of RS cells. Cytoplasmic immunostaining in the cells of the reactive cellular infiltrate was moderate. D: Moderate to strong PHD2 nuclear expression was found in RS cells. Moderate cytoplasmic immunostaining was apparent in most cells of the reactive cellular infiltrate. E: PHD3 expression was moderate to strongly nuclear in some $R S$ cells. In this case, the reactive cellular infiltrate was negative.

with limited-stage disease. HIF $1 \alpha$ has been linked to chemoresistance by inhibiting apoptosis and attenuating the rate of intracellular drug accumulation (28). A hypoxic

environment causes radioresistance, mainly due to reoxygenation and ROS formation, which enables stabilization of the DNA damage response (29). Activated HIF brings 


\section{A}

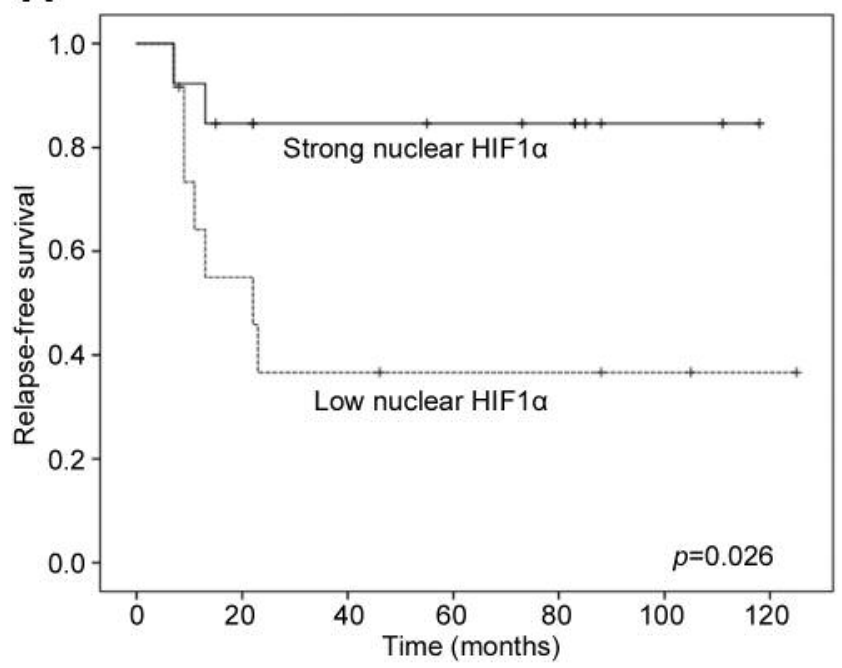

B

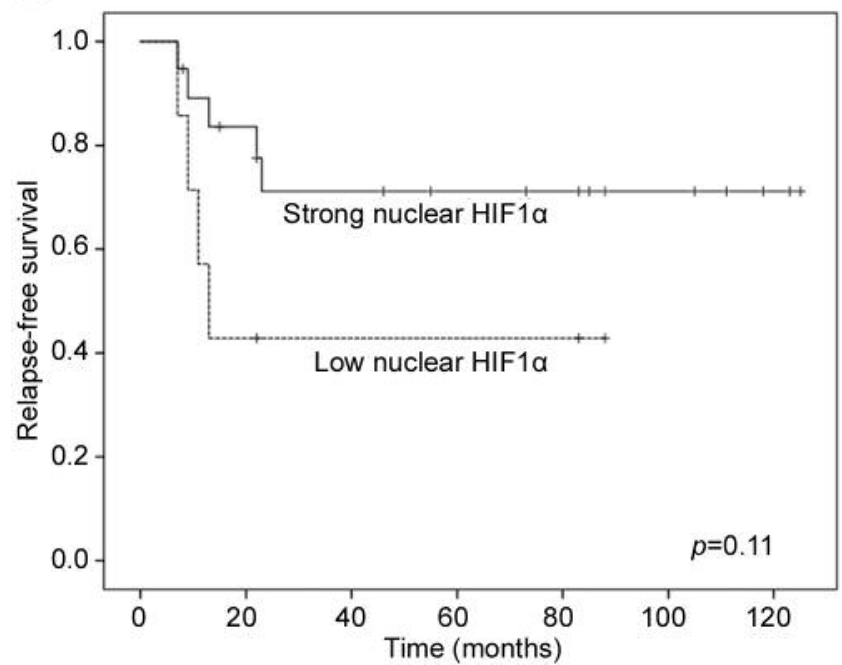

C

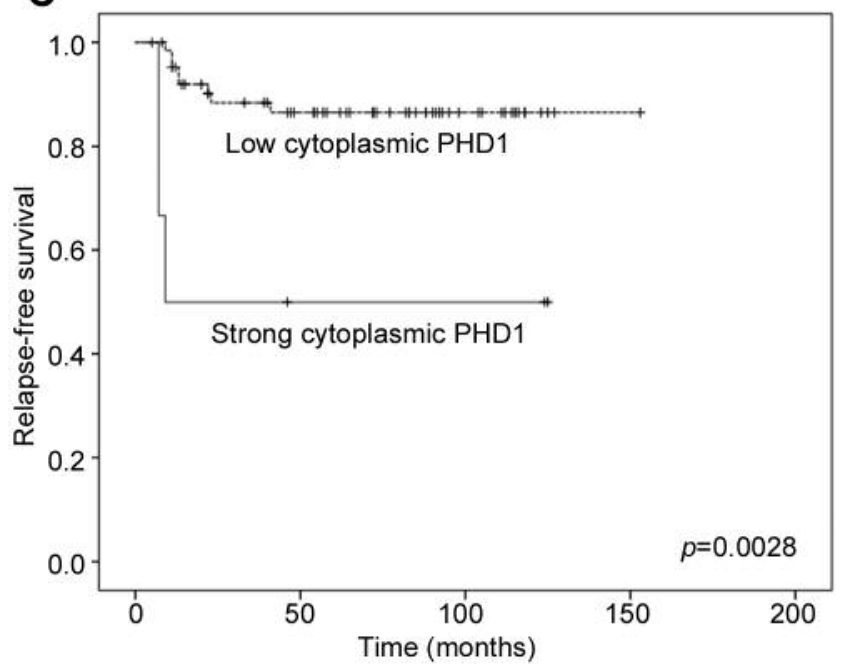

D

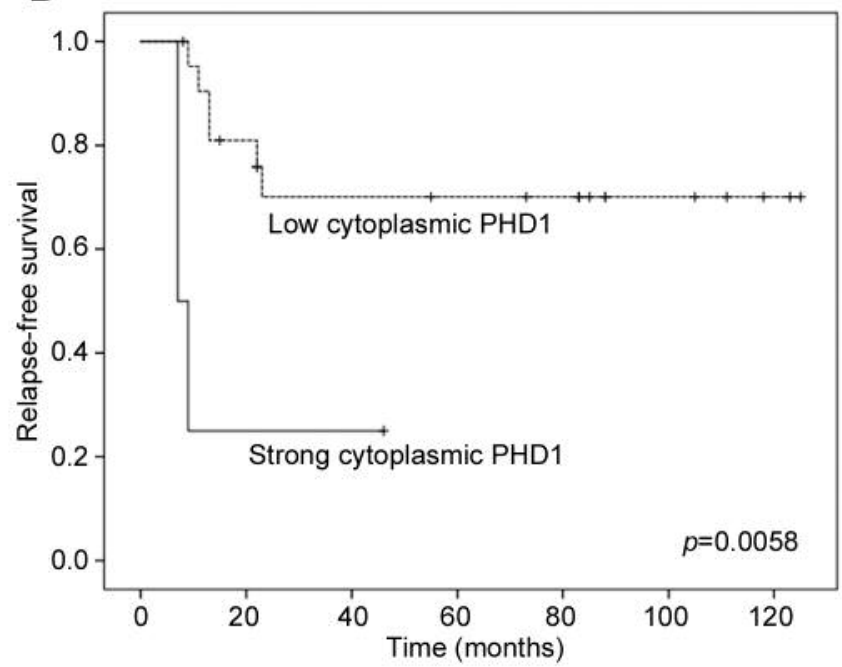

Figure 2. Kaplan-Meier analysis of relapse-free survival in patients with advanced-stage disease who had received involved-field radiotherapy according to nuclear hypoxia-inducible factor $1 \alpha(H I F 1 \alpha)$ expression in reactive cellular infiltrate (A), nuclear HIFl $\alpha$ expression in Reed-Sternberg $(R S)$ cells $(B)$, cytoplasmic prolyl hydroxylase domain 1 (PHD1) expression in RS cells $(C)$, and cytoplasmic PHD1 expression in RS cells (D).

about target gene expression and epigenetic post-translational histone modifications, which partly cause radiotherapy resistance (30). We have also shown that strong expression of the epigenetic regulators lysine $(\mathrm{K})$-specific demethylase 4B (KDM4B) and KDM4D are linked to radioresistance in cHL (31).

Strong nuclear HIF1 $\alpha$ expression in reactive cellular infiltrate was associated with prolonged RFS. There was also a similar tendency among the patients with advanced-stage cHL who received both ABVD and IFRT, although this observation was not statistically significant. HIF $1 \alpha$ has been linked to inferior survival in most types of cancer (8).
However, there are results concerning renal cell carcinoma, diffuse large B-cell lymphoma and head and neck squamocellular carcinoma where HIF1 $\alpha$ has been linked to improved survival (32-34). HIF1 $\alpha$ contributes to regulatory Tcell (Treg) differentiation and in cHL, Tregs have an essential role in reactive cellular infiltrate by providing vital survival signals for the RS cells $(35,36)$. On the other hand, the high proportion of active Tregs in reactive cellular infiltrate has been associated with a favourable prognosis in patients with HL (37, 38). Furthermore, we reported earlier that strong expression of the oxidative stress marker 8-hydroxydeoxyguanosine (8$\mathrm{OHdG}$ ) predicts prolonged RFS in advanced stages of $\mathrm{cHL}$ 
(39). Hypoxia produces oxidative stress via ROS generation and a strong positive correlation between $8-\mathrm{OHdG}$ and HIF1 $\alpha$ has been reported in healthy humans (40).

In conclusion, expression of HIF $1 \alpha$, HIF $2 \alpha$, PHD1 and PHD3 was associated with treatment resistance in cHL. Expression of PHD1 and HIF1 $\alpha$ may predict RFS, but this varies depending on the cellular compartment of expression and the stage of the disease. Hypoxia biomarkers could be promising as predictive factors as regards treatment response, but our findings should be confirmed in a larger independent patient population.

\section{Competing Interests}

None.

\section{Funding}

The Finnish Cancer Society, the Finnish Antituberculosis Association for support, Väisänen Fund in Terttu Foundation of North-Finland Healthcare Support.

\section{Acknowledgements}

The Authors thank Anne Bisi for her help with immunohistochemical staining.

\section{References}

1 Swerdlow SH, Campo E, Pileri SA, Harris NL, Stein H, Siebert R, Advani R, Ghielmini M, Salles GA, Zelenetz AD and Jaffe ES: The 2016 revision of the World Health Organization classification of lymphoid neoplasms. Blood 127: 2375-2390, 2016.

2 Bazzeh F, Rihani R, Howard S and Sultan I: Comparing adult and pediatric Hodgkin lymphoma in the Surveillance, Epidemiology and End Results Program, 1988-2005: an analysis of 21734 cases. Leak Lymphoma 51: 2198-2207, 2010.

3 van Nimwegen FA, Schaapveld M, Janus CP, Krol AD, Petersen EJ, Raemaekers JM, Kok WE, Aleman BM and van Leeuwen FE: Cardiovascular disease after Hodgkin lymphoma treatment: 40-year disease risk. JAMA Intern Med 175: 1007-1017, 2015.

4 Schaapveld M, Aleman BM, van Eggermond AM, Janus CP, Krol AD, van der Maazen RW, Roesink J, Raemaekers JM, de Boer JP, Zijlstra JM, van Imhoff GW, Petersen EJ, Poortmans PM, Beijert M, Lybeert ML, Mulder I, Visser O, Louwman MW, Krul IM, Lugtenburg PJ and van Leeuwen FE: Second cancer risk up to 40 years after treatment for Hodgkin's lymphoma. N Engl J Med 373: 2499-2511, 2015.

5 Evens AM, Hutchings M, Diehl V: Treatment of Hodgkin lymphoma: The past, present, and future. Nat Clin Pract Oncol 5: 543-556, 2008

6 Semenza GL: Oxygen sensing, homeostasis, and disease. N Engl J Med 365: 537-547, 2011.

7 Kaelin WG and Jr Ratcliffe PJ: Oxygen sensing by metazoans: the central role of the HIF hydroxylase pathway. Mol Cell 30: 393-402, 2008.
8 Semenza GL: Targeting HIF-1 for cancer therapy. Nat Rev Cancer 3: 721-732, 2003.

9 Rey S and Semenza GL: Hypoxia-inducible factor-1-dependent mechanisms of vascularization and vascular remodelling. Cardiovasc. Res 86: 236-242, 2010.

10 Gordan JD, Thompson CB and Simon MC: HIF and c-Myc: Sibling rivals for control of cancer cell metabolism and proliferation. Cancer Cell 12: 236-242, 2010.

11 Khan MN, Bhattacharyya T, Andrikopoulos P, Esteban MA, Barod R, Connor T, Ashcroft M, Maxwell PH and Kiriakidis S: Factor inhibiting HIF (FIH-1) promotes renal cancer cell survival by protecting cells from HIF-1 $\alpha$-mediated apoptosis. $\mathrm{Br}$ J Cancer 104: 1151-1159, 2011.

12 Fukuda R, Zhang H, Kim JW, Shimoda L, Dang CV and Semenza GL: HIF-1: regulates cytochrome oxidase subunits to optimize efficiency of respiration in hypoxic cells. Cell 129: 111-122, 2007.

13 Talks KL, Turley H, Gatter KC, Maxwell PH, Pugh CW, Ratcliffe PJ and Harris AL: The expression and distribution of the hypoxia-inducible factors HIF-1alpha and HIF-2alpha in normal human tissues, cancers, and tumor-associated macrophages. Am J Pathol 157: 411-421, 2000.

14 Epstein AC, Gleadle JM, McNeill LA, Hewitson KS, O'Rourke J, Mole DR, Mukherji M, Metzen E, Wilson MI, Dhanda A, Tian YM, Masson N, Hamilton DL, Jaakkola P, Barstead R, Hodgkin J, Maxwell PH, Pugh CW, Schofield CJ and Ratcliffe PJ: $C$. elegans EGL-9 and mammalian homologs define a family of dioxygenases that regulate HIF by prolyl hydroxylation. Cell 107: 43-54, 2001.

15 Berra E, Benizri E, Ginouvès A, Volmat V, Roux D and Pouysségur J: HIF prolyl- hydroxylase 2 is the key oxygen sensor setting low steady-state levels of HIF-1 $\alpha$ in normoxia. EMBO J 22: 4082-4090, 2003.

16 Xie L, Pi X, Mishra A, Fong G, Peng J and Patterson C: PHD3dependent hydroxylation of HCLK2 promotes the DNA-damage response. J Clin Invest 122: 2827-2836, 2012.

17 Aragonés J, Schneider M, Van Geyte K, Fraisl P, Dresselaers T, Mazzone M, Dirkx R, Zacchigna S, Lemieux H, Jeoung NH, Lambrechts D, Bishop T, Lafuste P, Diez-Juan A, Harten SK, Van Noten P, De Bock K, Willam C, Tjwa M, Grosfeld A, Navet R, Moons L, Vandendriessche T, Deroose C, Wijeyekoon B, Nuyts J, Jordan B, Silasi-Mansat R, Lupu F, Dewerchin M, Pugh C, Salmon P, Mortelmans L, Gallez B, Gorus F, Buyse J, Sluse F, Harris RA, Gnaiger E, Hespel P, Van Hecke P, Schuit F, Van Veldhoven P, Ratcliffe P, Baes M, Maxwell P and Carmeliet P: Deficiency or inhibition of oxygen sensor PHD1 induces hypoxia tolerance by reprogramming basal metabolism. Nat Genet 40: 170-180, 2008.

18 Klotzsche-von Ameln A1, Muschter A, Mamlouk S, Kalucka J, Prade I, Franke K, Rezaei M, Poitz DM, Breier G and Wielockx B: Inhibition of HIF prolyl hydroxylase-2 blocks tumor growth in mice through the antiproliferative activity of TGF $\beta$. Cancer Res 71: 3306-3316, 2011.

19 Fox SB, Generali D, Berruti A, Brizzi MP, Campo L, Bonardi S, Bersiga A, Allevi G, Milani M, Aguggini S, Mele T, Dogliotti L, Bottini A and Harris AL: The prolyl hydroxylase enzymes are positively associated with hypoxia-inducible factor- $1 \alpha$ and vascular endothelial growth factor in human breast cancer and alter in response to primary systemic treatment with epirubicin and tamoxifen. Breast Cancer Res 13: R16, 2011. 
20 Cummins EP, Berra E, Comerford KM, Ginouves A, Fitzgerald KT, Seeballuck F, Godson C, Nielsen JE, Moynagh P, Pouyssegur J and Taylor CT: Prolyl hydroxylase-1 negatively regulates IkappaB kinase-beta, giving insight into hypoxiainduced NFkappaB activity. Proc Natl Acad Sci USA 103: 18154-18159, 2006.

$21 \mathrm{Fu} \mathrm{J}$ and Taubman MB: Prolyl hydroxylase EGLN3 regulates skeletal myoblast differentiation through an NF-kappaBdependent pathway. J Biol Chem 285: 8927-8935, 2010.

22 Bargou RC, Emmerich F, Krappmann D, Bommert K, Mapara MY, Arnold W, Royer HD, Grinstein E, Greiner A, Scheidereit $\mathrm{C}$ and Dörken B: Constitutive nuclear factor-kappaB-RelA activation is require for proliferation and survival of Hodgkin's disease tumor cells. J Clin Invest 100: 2961-2969, 1997.

23 Garvalov BK, Foss F, Henze AT, Bethani I, Gräf-Höchst S, Singh D, Filatova A, Dopeso H, Seidel S, Damm M, AckerPalmer A and Acker T: PHD3 regulates EGFR internalization and signalling in tumours. Nat Commun 5: 5577, 2014.

24 Tennant DA and Gottlieb E: HIF prolyl hydroxylase-3 mediates alpha-ketoglutarate-induced apoptosis and tumor suppression. J Mol Med 88: 839-849, 2010.

25 Couvelard A, Deschamps L, Rebours V, Sauvanet A, Gatter K, Pezzella F, Ruszniewski P and Bedossa P: Overexpression of the oxygen sensors PHD-1, PHD-2, PHD-3, and FIH Is associated with tumor aggressiveness in pancreatic endocrine tumors. Clin Cancer Res 14: 6634-6639, 2008.

26 Boddy JL, Fox SB, Han C, Campo L, Turley H, Kanga S, Malone $\mathrm{PR}$ and Harris $\mathrm{AL}$ : The androgen receptor is significantly associated with vascular endothelial growth factor and hypoxia sensing via hypoxia-inducible factors HIF-1a, HIF$2 \mathrm{a}$, and the prolyl hydroxylases in human prostate cancer. Clin Cancer Res 11: 7658-7663, 2005.

27 Andersen S, Donnem T, Stenvold H, Al-Saad S, Al-Shibli K, Busund LT and Bremnes RM: Overexpression of the HIF hydroxylases PHD1, PHD2, PHD3 and FIH are individually and collectively unfavorable prognosticators for NSCLC survival. PLoS One 6: e23847, 2011.

28 Liu L, Ning X, Sun L, Zhang H, Shi Y, Guo C, Han S, Liu J, Sun S, Han Z, Wu K and Fan D: Hypoxia-inducible factor-1 alpha contributes to hypoxia-induced chemoresistance in gastric cancer. Cancer Sci 99: 121-128, 2008.

29 Wouters BG and Brown JM: Cells at intermediate oxygen levels can be more important than the "hypoxic fraction" in determining tumor response to fractionated radiotherapy. Radiat Res 147: 541-550, 1997.

30 Beyer S, Kristensen MM, Jensen KS, Johansen JV and Staller P: The histone demethylases JMJD1A and JMJD2B are transcriptional targets of hypoxia-inducible factor HIF. J Biol Chem 283: 36542-36552, 2008.

31 Bur H, Haapasaari KM, Turpeenniemi-Hujanen T, Kuittinen O, Auvinen P, Marin K, Soini Y and Karihtala P: Strong KDM4B and KDM4D expression associates with radioresistance and aggressive phenotype in classical Hodgkin lymphoma. Anticancer Res 36: 4677-4683, 2016.
32 Beasley NJ, Leek R, Alam M, Turley H, Cox GJ, Gatter K, Millard P, Fuggle S and Harris AL: Hypoxia-inducible factors HIF-1alpha and HIF-2alpha in head and neck cancer: relationship to tumor biology and treatment outcome in surgically resected patients. Cancer Res 62: 2493-2497, 2002.

33 Evens AM, Sehn LH, Farinha P, Nelson BP, Raji A, Lu Y, Brakman A, Parimi V, Winter JN, Schumacker PT, Gascoyne RD and Gordon LI: Hypoxia-inducible factor- $1 \alpha$ expression predicts superior survival in patients with diffuse large B-cell lymphoma treated with R-CHOP: J Clin Oncol 28: 1017-1024, 2010.

34 Lidgren A, Hedberg Y, Grankvist K, Rasmuson T, Vasko J and Ljungberg B: The expression of hypoxia-inducible factor 1alpha is a favorable independent prognostic factor in renal cell carcinoma. Clin Cancer Res 11: 1129-1135, 2005.

35 Dang EV, Barbi J, Yang HY, Jinasena D, Yu H, Zheng Y, Bordman Z, Fu J, Kim Y, Yen HR, Luo W, Zeller K, Shimoda L, Topalian SL, Semenza GL, Dang CV, Pardoll DM and Pan F: Control of T(H)17/T(reg) balance by hypoxia-inducible factor 1 . Cell 146: 772-784, 2011.

36 Marshall NA, Christie LE, Munro LR, Culligan DJ, Johnston PW, Barker R and Vickers MA: Immunosuppressive regulatory T-cells are abundant in the reactive lymphocytes of Hodgkin lymphoma. Blood 103: 1755-1762, 2004.

37 Schreck S, Friebel D, Buettner M, Distel L, Grabenbauer G, Young LS and Niedobitek G: Prognostic impact of tumourinfiltrating Th2 and regulatory T-cells in classical Hodgkin lymphoma. Hematol Oncol 27: 31-39, 2007.

38 Alvaro T, Lejeune M, Salvadó MT, Bosch R, García JF, Jaén J, Banham AH, Roncador G, Montalbán C and Piris MA: Outcome in Hodgkin's lymphoma can be predicted from the presence of accompanying cytotoxic and regulatory T-cells. Clin Cancer Res 11: 1467-1473, 2005.

39 Bur H, Haapasaari KM, Turpeenniemi-Hujanen T, Kuittinen O, Auvinen P, Marin K, Koivunen P, Sormunen R, Soini Y, Karihtala P: Oxidative stress markers and mitochondrial antioxidant enzyme expression are increased in aggressive Hodgkin lymphomas. Histopathology 65: 319-327, 2014.

40 Pialoux V, Mounier R, Brown AD, Steinback CD, Rawling JM and Poulin MJ: Relationship between oxidative stress and HIF1 alpha mRNA during sustained hypoxia in humans. Free Radic Biol Med 46: 321-326, 2009. 